\title{
ANALYZING THE MISTAKES AND DECEPTIONS OF ACCOUNTING IN TERMS OF BUSINESS ETHICS
}

\author{
DOI: 10.17261/Pressacademia.2020.1236
}

PAP- V.11-2020(8)-p.38-42.

\section{Beste Rodoplu ${ }^{1}$, Dilek Teker ${ }^{2}$}

${ }^{1}$ Isik University, Institute of Social Science, Istanbul, Turkey. beste rodoplu@hotmail.com, ORCID: 0000-0001-5508-4772

${ }^{2}$ Isik University, Faculty of Economics and Administrative Sciences, Department of Management, Istanbul, Turkey. dilek.teker@isikun.edu.tr. ORCID: 0000-0002-3893-4015

To cite this document

Rodoplu, B., Teker, D., (2020). Analyzing the mistakes and deceptions of accounting in terms of business ethics. PressAcademia Procedia (PAP), V.11, p.38-42.

Permanent link to this document: http://doi.org/10.17261/Pressacademia.2020.1236

Copyright: Published by PressAcademia and limited licensed re-use rights only.

\section{ABSTRACT}

Purpose- Ethic; It is the execution of the work within the framework of certain generally accepted rules while performing the profession. The purpose of this study is to examine the mistakes and deceptions in accounting within the framework of professional ethics, which is one of the key points in the performance of the profession.

Methodology- In today's technology world, mistakes are still made in accounting, there are many accountants who resort to deception and there are many taxpayers who made misleading requests for their interests.

Accordingly, a questionnaire study was conducted on accountants to reveal the causes of mistakes and deception, how they were encountered, the importance and place of ethics in preventing mistakes and deception. In the first part of the survey, nine demographic questions were asked to the participants. In the second part, the answers of the questions such as the accountant's approach to mistake and deception, the reasons that push the person towards the mistake and deception, the effects of ethics on mistake and deception, and unethical events they encounter in their professional lives were sought.

Findings- The questionnaire study includes the evaluation of mistake and deception in terms of ethics by the professional. Unfortunately, it seems that the deterrent elements were not sufficient to prevent cheating, in particular. For this, ethics education, ethics embedded in professional behavior and assimilation by professional accountants are very important.

Conclusion- Members of the profession can face situations where they can mistake and deception through many factors such as business gaps, customer incentives and legal gaps throughout their professional life. Ethics is the most important factor that enables the person to realize his / her professional responsibility correctly without any mistake and deception.

Keywords: Accounting, fraud and mistakes, ethics.

JEL Codes: M40, M41, M42

\section{MUHASEBEDE YAPILAN HATA VE HILELERIN MESLEKETiĞi AÇISINDAN INCELENMESi}

\section{ÖZET}

Amaç- Etik; mesleği icra ederken genel olarak kabul görmüşbelirli kurallar çerçevesinde işin yürütülmesidir. Bu çalışmanın amacı muhasebede yapılan hata ve hilelerin, mesleğin icra edilmesindeki kilit noktalardan biri olan mesleki etiği çerçevesinde incelenmesidir.

Yöntem- Günümüz teknoloji dünyasında hala muhasebede hatalar yapılmaktadır, hileye başvuran pek çok muhasebeci vardır ve çıkarları için yanıltıcı isteklerde bulunan birçok mükellef bulunmaktadır. Buna göre, hata ve hilenin nedenlerini, bunlarla ne şekilde karşılaşıldığını, etiğin hata ve hilelerin önlenmesindeki önemini ve yerini ortaya koymak için muhasebeciler üzerinde bir anket çalışması yapılmıştır. Anketin birinci bölümde katılımcılara dokuz adet demografik soru sorulmuştur. İkinci bölümde ise muhasebecinin hata ve hileye yaklaşımı, kişiyi hata ve hileye iten nedenler, etiğin hata ve hile üzerindeki etkileri, meslek hayatlarında karşılaştıkları etik dışı olaylar gibi sor uların yanıtları aranmıştır. Bulgular- Yapılan anket çalışması, hata ve hilenin meslek mensubu tarafından etik anlamında değerlendirilmesini içermektedir. Ancak, maalesef görülüyor ki caydırıcı unsurlar özellikle hilenin önüne geçmede yeterli olmamıştır. Bunun için etik eğitimi, etiğin mesleki davranışa işlemesi ve muhasebe meslek mensubu tarafından özümsenmesi çok önemlidir.

Sonuç- Meslek mensupları meslek hayatları boyunca gerek işletmede bulunan boşluklar, gerek müşteri teşvikleri, gerekse yasal boşluklar gib pek çok etkenler aracilıla hata ve hileye ortam sağlayabilecekleri durumlarla karşılaşabilmektedirler. Etik, bu durumlarda kişinin mesleki sorumluluğunu hata ve hileye imkân vermeden doğru bir şekilde gerçekleştirmesini sağlayan en önemli unsurdur.

Anahtar kelimeler: Muhasebe, hata ve hile, etik.

JEL Kodlari: M40, M41, M42 


\section{GíRiş}

'Mali işlem' niteliği taşıyan olayların geçerli para birimiyle ifade edilmek süratiyle kaydedilmesi, sınıflandırılması, özetle nerek anlamlı bir rapor haline getirilmesi ve sonuçların ilgili taraflara iletilmesi muhasebe süreci olarak adlandırılır. Günümüz ekonomi dünyasında, işletmelerin mali durumlarını anlayabilmek için kaydedilen bilgileri anlamlandırıp bu bilgilerden fayda sağlamak, ekonomik birimlerin finansal durumuyla alakalı eksiksiz bir şekilde bilgi edinebilmek ticari etkileşim açısından oldukça önemlidir. Muhasebe işlemlerinin sonuçlarında hile veya hatalardan kaynaklanan bazı problemler oluşabilir. Oluşan bu problemleri birbirinden ayıran en önemli etken bilinçli yapılıp yapılmadığıdır. Bilinçli olarak yapılan her yanlışlık hile olarak nitelendirilirken, bilmeden veya istemeyerek yapılan yanlışlıklar hata olar ak değerlendirilir. Hilelerin tespit edilmesi hataların tespitinden çok daha zordur ve bilinçli yapıldığı için muhasebe sistemi içinde kendiliğinden ortaya çıkamaz. Çünkü insan zekâsı her probleme bir çözüm üretebilmekte ve her geçen gün yeni yöntemler bulabilmektedir. Hilelerin ortaya çık masında en önemli unsur denetçinin tecrübe ve bilgisidir. Bu sebepten denetçilerin dikkatli olması ve şüpheci yaklaşması gerekir. Yapılan hata ve hileler işletmenin hem iç çevresini hem de dış çevresini ciddi boyutlarda etkileyen bir durumdur. Muhasebe mesleğini icra edenlerin hizmetlerinde sunduğu kalite ve güvenilirlik; gizlilik, sorumluluk, tarafsızlık gibi mesleğin etiğine uyan şekilde hareket etmelerine bağlıdır. Bu sebeple en önemli sayılabilecek kural; muhasebecilerin meslek etiğine uygun hizmet sunmalarıdır

Muhasebede etik; mesleği icra ederken genel olarak kabul görmüş belirli kurallar çerçevesinde işin yürütülmesidir. Genellikle meslek ahlakı olarak da isimlendirilir. Muhasebeciler etiğe uygun olarak hareket ederlerken bağlı oldukları işletmenin yanı sıra devlete ve topluma karşı da sorumludurlar. Etiğin muhasebe meslek mensuplarının sorumluluk ve iş ahlakı anlayışına iyice işleyebilmesi için, muhasebe eğitimi ile birlikte etik eğitimini de alması gereklidir. Türkiye'de ulusal düzeyde muhasebe meslek etiği kurallarına, 3568 sayılı kanunda yer verilmiştir. "3568 Sayılı Serbest Muhasebeciler, Serbest Muhasebeci Mali Müşavirler veYeminli Mali Müşavirlerin Mesleki Faaliyetlerinde Uyacakları Etik ilkeler Hakkında Yönetmelik" kapsamında meslek etiğinin ilkeleri şu şekilde özetlenmektedir; Dürüstlük illkesi, Mesleki Yeterlilik ve Özen İlkesi, Tarafsızıı ìlkesi, Mesleki Davranış İlkesi, Gizlilik illkesi. Bu çalışmada muhasebenin tanımı kısaca yapılmış; muhasebede hata ve hile nedir, aralarında farklar nelerdir, etik hata ve hilelerin önlenmesi açısından ne derece etkilidir gibi soruların yanıtları aranmıştır. Konuyla alakalı yapılan literatür çalışmasında muhasebe etiği eğitiminin etik değerler ile ilgili seminer, konferans, toplantı gibi etkinliklerle desteklenmesi gerektiği sonucuna varılmıştır. Zorlu pazar şartları nedeniyle işletmelerde çoğunlukla kar odaklı hedefler belirlendiği; bu durumun kişilerde değerler zıtlaşmasına neden olan bazı aksamalara yol açabildiği belirlenmiş, dolayısıyla kişileri bu tür aksamaların etik dışı davranışlara yönlendirebildiği saptanmıştır. Fakat bununla beraber muhasebe hata ve hilelerinin esas noktasında sadece muhasebe meslek mensuplarının değil mükelleflerin, hükümetin uyguladığı politikaların, vergi kanunlarının ve toplumsal yapı gibi faktörlerin de etkili olduğu görülmüştür.

\section{LITERATÜR INCELEMESi}

Maliye Hesap Uzmanları Derneği (2004), muhasebede hatanın bilinçsizce, istemeyerek gerçekleştiğini; hilenin ise bilerek, isteyerek, bilinçlice yapıldığını, bu nedenle hilelerin tespitinin son derece zor olduğu ve bilinçli yapıldığı için muhasebe sistemi içinde kendiliğinden ortaya çıkmayacağı belirtilmiştir. Emir (2008), finansal tablodaki yanlışlıkların hileden, usulsüzlükten veya hatadan kaynaklandığı belirtmiş, hileyi hatadan ayıran temel unsurun, finansal tablolarda yanlışlığa sebep olan hareketin biler ek ve isteyerek yapılıp yapılmadığı olarak tanımlamıştır. Müslümov ve Aras (2002) etiğin yaşamın her alanında davranışları yönlendiren standartların ve ilkelerin bütünü olarak algılandığını; yaşanılan toplumun geleneklere, bazı durumlarda ise meslek gruplarının özelliklerine bağlı olarak biçimlendiğini söylemişlerdir. Bayrak (2001) kitabında etik ve ahlak kavramlarını birbirleriyle ilişkilendirirken aralarındaki temel farkı etiğin ahlakı da kapsayan felsefi bir disiplin olduğunu belirtmiştir. Etiğin tanımını toplum tarafından kabul edilen ilkeler bütünü şeklinde yaparken; ahlakı ise, bireylerin bulunduğu yer ve geleneğe göre kendine uygun davranışta bulunma ve karar alma olarak tanımlamıştır. Ağyar, Kutluk, ve Cengiz (2012), muhasebeci adayları ve meslek yüksekokullarında muhasebe eğitimi gören öğrencilerin meslek etiğine bakış açılarını inceleyen çalışmasında meslek etiği ile ilg ili derslerin yanı sıra etik değerler ile ilgili seminer, konferans, toplantı gibi etkinliklerle muhasebe etiği eğitiminin desteklenmesi gerektiğini belirtmişlerdir. Meslek etiğini etkileyen faktörleri cinsiyet, yaş, gelir durumu, mezun olunan bölüm, ailenin eğitim durumu şeklinde sıralamışlardır. Ayrıca cinsiyetin meslek etiği ile ilgili yargılarda farklılık yarattığı, kadın öğrencilerin erkeklere göre etik davranışları daha çok önemsedikleri ve daha fazla etik davranışta bulunduğu saptanmıştır. Meslek etiği kavramının yaş ilerledikçe bireylerde daha çok önemsenen bir kavram olduğu, meslek lisesinden mezun olan öğrencilerin muhasebe ile ilgili bölümlerden mezun olan öğrencilere göre daha düşük etik duyarlılı̆a sahip olduğu belirlenmiş olup, bu durumda muhasebe etik eğitiminin meslek liselerinden itibaren müfredata konması gerektiği sonucuna ulaşıımıştır. Keskin (2014), çalışmasında insanı hileye iten sebepleri sınırlandırmanın doğru olmadığını, hileye; dürtülerin uygun zamanda uyanmasının sebep olduğunu belirtmiştir. Kişinin hileye başvurmasında baskı, fırsat ve kendini haklı gösterme faktörlerinin etkili olduğunu ve bunlara 'hile üçgeni' dendiğini açıklamıştır. Erkan (2003), araştırmasında acımasız pazar şartlarının işletme yapılarını, ayakta kalabilme pahasına yalnızca kâr hedefli davranışlara itebildiğini söylemiştir. Bu durumun, toplumların geçmişten beri sahip oldukları değerlerin insan merkezli bakışında düşünce-davranış zıtlaşmasına neden olan bir kısım aksamalara yol açabildiğini belirtmiştir. Dolayısıyla kişileri bu tür aksamaların etik dışı davranışlara yönelttiğini; böyle bir davranışa yönelmenin genelde temel nedeninin ise "Bu eylem ya da davranışla bir çıkar elde edebilir miyim?” düşüncesinin oluşturduğunu anlatmıştır. Kısakürek ve Alpan (2010), muhasebe meslek etiğini; meslek mensuplarının mesleki faaliyetlerini yürütürken kanunlara uygun işlem yapmasının yanı sıra toplumun değer yargılarını dikkate alarak güvenilir, ilgili, anlaşılabilir, doğru, tutarlı bilgilerin topluma sunulması ve müşteriler, toplum, meslektaşlar ve ilgili m eslek kuruluşları ile olan ilişkilerde uyulması gereken kurallar bütünü şeklinde tanımlamışlardır. Türkiye' de muhasebe meslek etiği ile yapılan düzenlemelerde; mesleki yeterlilik, bağımsızlık ilkeleri, mesleki özen ve titizlik, ticaret ve mesleğe aykırı faaliyet yasağı, reklâm yasağı, sır saklama yükümlülüğü, karşılıkı ilişkiler ve haksız rekabet ve ekip çalışmasında görev, yetki ve sorumluluk dağılımı gibi başlıkların dikkat çekmekte olduğunu belirtmişlerdir. Wolfe ve Hermanson (2004), çalışmalarında hileye etken bir dördüncü neden olarak 'yetkinlik' maddesinin bulunduğunu anlatmışlardır. Hile karosu ismiyle bilinen teori için, hile üçgenini oluşturan faktörler bulunsa bile bunları fırsata çevirmek için donanım ve bilgiye sahip olmayan kişinin hileyi gerçekleştirmesinin zor olacağından bahsetmişlerdir. Bu dördüncü etken kişinin doğuştan gelen yetenekleri ve sonradan kazandığı becerileri yani "yetkinlikleri"dir. Hile karosu ismiyle bilinen teori, hile üçgeninde bulunan fırsat mevcudiyeti, baskı ve haklı gösterme etkenlerinin bulunması halinde bile bu unsurları fırsata çevirebilecek donanım ve bilgiye sahip olmayan bir kişinin hileyi ge rçekleştirmesinin daha zor olduğunu anlatır. "Hile şansını görerek bundan kim faydalanabilir?" sorusu sorularak, yetkinlik etkeninin hile üçgenindeki unsurlara 
ek olarak hile riskinin değerlendirilmesinde incelenmesi gerekmektedir. Kirik (2007) tarafından yapılan muhasebede hata ve hile ile ilgili bir çalışmada muhasebe hata ve hilelerinin esas noktasında sadece muhasebe meslek mensupları değil mükelleflerin, hükümetin uyguladığı politikaların, vergi kanunlarının ve toplumsal yapı gibi faktörlerin de etkili olduğu ifade edilmektedir. Muhasebe işlemlerin in kayıtlara geçirilmesi sırasında mükellefler tarafından yapılan baskıların, meslek mensuplarını güç durumda bıraktığı, meslek mensuplarının kamu menfaatleri ile mükellef menfaatleri arasında kaldıkları, vergi denetimlerinin yeterli olmaması, vergi yasalarında bulunan boşluklar ve muhasebe meslek mensuplarının mükelleflere ekonomik yönden bağımlı olmasının mükelleflerin baskılarını arttırmasında önemli bir neden olduğu tespit edilmiştir. Civelek ve Durukan (1997) araştırmalarında muhasebe mesleği ile uğraşan kişilerin; devlete, topluma, mesleki kuruluşlara, müşterilerine ve kendilerine karşı sorumlulukları olduğundan bahsetmişlerdir. Buna göre muhasebe meslek mensubunun karşı karşıya olduğu sorumlulukları şöyle açıklamışlardır:

1. 1.Devlete Karşı: Yasaların belirttiği doğruları yapmak, gerçekleri çarpıtmamak ve devletin çıkarlarını gözetmek.

2. 2.Topluma Karşı: Toplumun güvenini sarsıcı, toplumu yanıltıcı "finansal mesajlar" vermekten kaçınmak, toplumun genel çıkarları konusunda duyarlı olmak.

3. 3. Mesleki Kuruluşlarına Karşı: Mesleki kuruluşların muhasebe mesleğinin imajını, saygınlığını sağlama amacı ile belirlediği standart ve kurallara uygun davranı̧ ve faaliyetlerde bulunmak.

4. 4.Müşterilere Karşı: Müşteriye profesyonelce hizmet vermek yani müşterinin çıkarlarını gözetmek, yol gösterici olmak, müşteri ile ilgili edinilen özel bilgileri saklı tutma da güvenilir olmak.

5. 5.Kendisine Karşı: Kişisel disiplin sahibi olmak, mesleki konularda sürekli olarak kendisini geliştirebilmek, yasa ve yönetme liklere uyarak kamu ve toplum yararına uygun davranış biçimleri sergilemek.

\section{VERI VE YÖNTEM}

Bu anket çalışmasının amacl; muhasebe meslek mensuplarını hata ve hileye yönelten sebeplerin tespit edilmesi, etiğin mesleki sorumlulukların yerine getirirken ne derece etkili ve önemli olduğunun incelenmesidir. Hilelere başvuran birçok meslek mensubu ve menfaatleri uğruna yanıltıcı isteklerde bulunan birçok mükellef bulunmaktadır. Bu doğrultuda anket; hata ve hilenin nedenlerini, bunlarla ne şekilde karşılaşıldığını, etiğin hata ve hilelerin önlenmesindeki önemini ve yerini ortaya koymaktadır. Anket iki ayrı bölümden oluşmaktadır. Birinci bölümde meslek mensubunun yaşı, eğitim düzeyi, mesleki unvanı gibi demografik bilgilere ulaşılması amaçlanmış, bu doğrultuda dokuz adet soru sorulmuştur. İkinci bölümde ise meslek mensubunun hata ve hileye yaklaşımı, kişiyi hata ve hileye iten nedenler, etiğin hata ve hile üzerindeki etkileri, meslek hayatlarında karşılaştıkları bazı etik dışı olaylar gibi soruların yanıtları aranmıştır.

Araştırmanın doğrultusunda seçilmiş bazı bulgular aşağıda sunulmuuştur.

Bulgu $_{1}$ : Muhasebe standartlarına uyulduğu gibi mesleki etik kurallarına uyulması hata ve hilelerin en aza indirilmesinde etkilidir.

\begin{tabular}{|l|c|c|c|}
\hline $\begin{array}{l}\text { Meslek hayatım süresince her zaman teknik, } \\
\text { mesleki standartlara uyan bir şekilde } \\
\text { hareket ettim }\end{array}$ & $N$ & Yüzde & $\begin{array}{c}\text { Ölçek } \\
\text { Derecesi }\end{array}$ \\
\cline { 1 - 3 } Katılıyorum & 45 & 69,2 & \\
\hline Kısmen katılıyorum & 16 & 24,6 & \multirow{2}{*}{4,63} \\
\cline { 1 - 3 } Kararsızım & 4 & 6,2 & \\
\cline { 1 - 3 } Kısmen katılmıyorum & 0 & 0 & \\
\hline Katılmıyorum & 0 & 0 & \\
\hline Total & 65 & 100,0 & \\
\hline
\end{tabular}

\begin{tabular}{|l|c|c|c|}
\hline $\begin{array}{l}\text { Meslek mensubu olarak Meslek Ahlak } \\
\text { Kurallarını göz önünde bulundurduğumda } \\
\text { mesleki açıdan bu kurallara uygun hareket } \\
\text { ettiğimi düşünüyorum. }\end{array}$ & $\mathrm{N}$ & Yüzde & $\begin{array}{c}\text { Ölçek } \\
\text { Derecesi }\end{array}$ \\
\hline Katılıyorum & 46 & 70,8 & \\
\hline Kısmen katılıyorum & 11 & 16,9 & \multirow{2}{*}{4,55} \\
\hline Kararsızım & 6 & 9,2 & \\
\hline Kısmen Katılmıyorum & 2 & 3,1 & \\
\cline { 1 - 3 } Katılmıyorum & 0 & 0 & \\
\hline Total & 65 & 100,0 & \\
\hline
\end{tabular}

\begin{tabular}{|l|c|c|c|}
\hline $\begin{array}{l}\text { Meslek Yasasına aykırı davranışlardan } \\
\text { dolayı şimdiye kadar herhangi bir ceza } \\
\text { almadım. }\end{array}$ & Seçenek & $\mathrm{N}$ & $\begin{array}{c}\text { Observed } \\
\text { Prop. }\end{array}$ \\
\hline Group 1 & Evet & 53 &, 82 \\
\hline Group 2 Hayır & 12 &, 18 \\
\hline Total & & 65 & 1,00 \\
\hline
\end{tabular}


Ankette, kişilerin meslek standartlarına uyma oranı $\% 69,2$, mesleki etiğe uyma oranı \%70,8 olarak görüşmüştür. \%82'lik dilim de meslek yasasına aykırılıktan dolayı herhangi bir ceza almamıştır. Bu üç orana bakılarak Bulgu ${ }_{1}^{\prime}$ in doğrulandığı söylenebilir. Yani meslek mensubu, meslek yasasına ve mesleki etik standartlarına uygun davrandığı takdirde hile ve hatalar en aza indirilebilmektedir.

Bulgu $_{2}$ : Yasal boşluklar olsa dahi meslek mensubu mesleğini icra ederken etik kuralları göz önünde bulundurup ona göre davranmalıdır .

\begin{tabular}{|l|c|c|c|}
\hline $\begin{array}{l}\text { Meslek mensuplarının yasa ile } \\
\text { belirlenmiş durumların yetersiz kaldığ } \\
\text { olaylarla karşılaşsalar bile etik ilkelerine } \\
\text { bağlı kaldıklarını düşünüyorum }\end{array}$ & $\mathrm{N}$ & Yüzde & $\begin{array}{c}\text { Ölçek } \\
\text { Derecesi }\end{array}$ \\
\hline Katılıyorum & 17 & 26,2 & \\
\hline Kısmen katılıyorum & 20 & 30,8 & \multirow{2}{*}{$\mathbf{3}, \mathbf{4 4}$} \\
\hline Kararsızım & 11 & 16,9 & \\
\hline Kısmen Katılmıyorum & 9 & 13,8 & \\
\hline Katılmıyorum & 8 & 12,3 & \\
\hline Total & 65 & 100,0 & \\
\hline
\end{tabular}

“Meslek mensuplarının yasa ile belirlenmiş durumların yetersiz kaldığı olaylarla karşılaşsalar bile etik ilkelerine bağlı kaldıklarını düşünüyorum." sorusuna anket katılımcılarının \%26,2'si 'Katılıyorum' seçeneğini işaretlerken, \%30,8'i kısmen katılıyorum şeklinde yanıt vermiştir.

Bulgu 3 : Meslek mensuplarınca, meslek ahlakına uymayan davranış veya işlem yapanlara verilen cezalar yeterlidir.

\begin{tabular}{|l|c|c|c|}
\hline $\begin{array}{l}\text { Meslek mensuplarınca, meslek ahlakına } \\
\text { uymayan davranış veya işlem yapanlara } \\
\text { verilen cezaları yeterli buluyorum. }\end{array}$ & $N$ & Yüzde & $\begin{array}{c}\text { Ölçek } \\
\text { Derecesi }\end{array}$ \\
\cline { 1 - 3 } Evet & 35 & 53,8 & \\
\hline Kısmen evet & 12 & 18,5 & \multirow{2}{*}{$\mathbf{4 , 0 3}$} \\
\cline { 1 - 3 } Kararsızım & 9 & 13,8 & \\
\cline { 1 - 3 } Kısmen hayır & 3 & 4,6 & \\
\cline { 1 - 3 } Hayır & 6 & 9,2 & \\
\hline Total & 65 & 100,0 & \\
\hline
\end{tabular}

Anket katılımcılarının \%53,8'i bu tip meslek ahlakına uymayan davranış ve işlemlere verilen cezaları yeterli bulmuştur. Cezalar, hata ve özellikle hile yapma hususundaki en büyük caydırıcı etkendir. Bu sonuç, hata ve hilelerin azaltılması kapsamında değerlendirildiğinde oldukça iyidir.

Bulgu ${ }_{4}$ : Denetim boşlukları, vergi oranlarının fazla olması gibi hileye ortam hazırlayan olaylar meslek mensubunu hata veya hile yapmaya itmemelidir.

\begin{tabular}{|l|c|c|c|}
\hline $\begin{array}{l}\text { Denetimin yetersiz olması yapılan hata } \\
\text { ve hileler üzerinde etkilidir. }\end{array}$ & N & Yüzde & $\begin{array}{c}\text { Ölçek } \\
\text { Derecesi }\end{array}$ \\
\cline { 1 - 2 } Katılıyorum & 33 & 50,8 & \\
\hline Kısmen katılıyorum & 16 & 24,6 & \multirow{2}{*}{$\mathbf{4 , 0 7}$} \\
\cline { 1 - 3 } Kararsızım & 8 & 12,3 & \\
\cline { 1 - 3 } Kısmen Katılmıyorum & 4 & 6,2 & \\
\cline { 1 - 3 } Katılmıyorum & 4 & 6,2 & \\
\cline { 1 - 3 } Total & 65 & 100 & \\
\hline
\end{tabular}

\begin{tabular}{|l|c|c|c|}
\hline $\begin{array}{l}\text { Vergi kanunlarındaki boşluklarda n } \\
\text { yararlanmayı_doğru buluyorum. }\end{array}$ & $\mathrm{N}$ & Yüzde & $\begin{array}{c}\text { Ölçek } \\
\text { Derecesi }\end{array}$ \\
\cline { 1 - 3 } Evet & 6 & 9,2 & \\
\hline Kısmen evet & 12 & 18,5 & $\mathbf{2 , 3 5}$ \\
\hline Kararsııım & 11 & 16,9 & \\
\hline Kısmen hayır & 6 & 9,2 & \\
\hline Hayır & 30 & 46,2 & \\
\cline { 1 - 3 } Total & 65 & 100,0 & \\
\hline
\end{tabular}


Katlımcıların $\% 50,8^{\prime} i$ denetim yetersizliğinin hata ve hileye sebebiyet verdiğini düşünmektedir. $\% 46,2^{\prime}$ lik dilim vergi boşluklarından yararlanmayı etik bulmamaktadır. Denetim boșlukları, vergi oranlarının fazla olması gibi hileye ortam hazırlayan olaylar meslek mensubunu hata veya hile yapmaya itmemelidir.

Bulgu s: Meslek mensuplarının etik eğitimi alması, hata ve hilelerin azaltılmasında etkili bir faktördür.

\begin{tabular}{|c|c|c|c|}
\hline $\begin{array}{l}\text { Muhasebe meslek mensuplarının, } \\
\text { muhasebe eğitimi ile birlikte etik } \\
\text { eğitimi almaları da gerekir. }\end{array}$ & $\mathrm{N}$ & Yüzde & $\begin{array}{c}\text { Ölçek } \\
\text { Derecesi }\end{array}$ \\
\hline Katılıyorum & 44 & 67,7 & \\
\hline KIsmen katıllyorum & 15 & 23,1 & \multirow[t]{5}{*}{4,5} \\
\hline Kararsızım & 2 & 3,1 & \\
\hline Kısmen Katılmıyorum & 3 & 4,6 & \\
\hline Katılmıyorum & 1 & 1,5 & \\
\hline Total & 65 & 100,0 & \\
\hline
\end{tabular}

Anketi uygulayan meslek mensuplarının \%67,6'si muhasebe meslek mensuplarının, muhasebe eğitimi ile birlikte etik eğitimini de almaları gerektiğini düşünmektedir. Etiğe uymak, temelinde kişinin ahlaka bakışılla doğru orantılıdır. Ancak kişileri etiğe bir yandan da teşvik etmek, bazı durumlarda kişinin henüz farkında olmadı̆̆ı doğruluk ilkelerini keşfetmelerine yardımcı olabilir. Bu yüzden etik eğitiminin önemli olduğu söylemek mümkündür.

\section{SONUÇ}

Araştırma, meslek mensubunu hata ve/veya hile eyleminde bulunmasının sebebini, karşılaştı̆̆ı hatalar/ hileler karşısındaki tutumunu, etik kavramını meslek ahlakı açııından nasıl değerlendirdiğini veya ne derece önemli bulduğunu ortaya çıkarmayı amaçlamaktadır. İşletmelerin ve bilgi kullanıcıarının muhasebeden en önemli beklentisi, kaydedilip sınıflandııılan finansal bilgilerin doğru bir şekilde raporlanmasıdır. Her sistemde olduğu gibi muhasebe sisteminde de hataya sebebiyet veren bir takım dikkatsizlikler mevcuttur. Çift kayıt sistemi ve özellikle teknolojinin hayatın bir parçası haline gelmesi, muhasebe hatalarııı neredeyse sıfır düzeyine indirmiştir. Ancak hile, kişile rin bilinçli olarak yaptı̆̆ yanıltmalar olduğu için hata kadar kolay tespit edilememektedir. Bu hata ve hilelerin ortadan kalkması için çeşitli denetim çalışmaları, caydırıc cezalar, Muhasebe Standartları gibi meslek mensubunun faaliyetlerini belirli meslek ilkeleri çerçevesinde sınırlayan etkenlerin yanında muhasebeden beklenen güveni tam olarak sağlamak, kişinin mesleki ahlakına, etik anlayışına bağlıdır.

\section{KAYNAKÇA}

Ağyar, E., Kutluk, F. ve Cengiz, E., (2012). Meslek Yüksek Okulları Muhasebe Bölümü Öğrencilerinin Sosyo-Ekonomik Değişkenler Işığında Mesleki Etiğe Bakış Açılarının İncelenmesi (Akdeniz Üniversitesi Örneği). Journal of Yasar University, Sayı: 25, ss.4203-4228.

BAYRAK, S., (2001). İş Ahlakı ve Sosyal Sorumluluk. Beta Basın Yayım Dağııım A.Ş., İstanbul.

Civelek, M. A., \& Durukan, M. B. (1997). Günümüz Koşullarında Muhasebe Mesleği ve Meslek Ahlakı. III. Türkiye Muhasebe Denetimi Sempozyumu, Muhasebe Denetimi Mesleğinde Yetkiler, Sorumluluklar ve Meslek Ahlakı. ISMMO Yayınları,Sayı:20, ss.31-13.

Emir, M., (2008). Hile Denetimi. Mali Çözüm Dergisi. Sayı.86, ss.109-121.

Gürbüz, H., (1995). Muhasebe Denetimi. Bilim Teknik Yayınevi, İstanbul.

Keskin, S., (2014). Muhasebe Hata ve Hileleri Karşısında Etik Tutumlar: Meslek Mensupları Üzerine Bir Araştırma. Süleyman Demirel Üniversitesi, Sosyal Bilimler Enstitüsü, Yayınlanmamış Yüksek Lisans Tezi", Isparta.

Kirik, Z.., (2007). Muhasebe Hata Hileleri ile Muhasebe Mesleğinde Etik: Afyon Karahisar'da Muhasebeciler Üzerine Bir Araştırma. Eskişehir Anadolu Üniversitesi, Sosyal Bilimler Enstitüsü (Yayınlanmış Yüks ek Lisans Tezi), Eskişehir.

Kısakürek, M., Alpan, N., (2010). Muhasebe Meslek Etiği ve Sivas ilinde Bir Uygulama. Muhasebe ve Finans Dergisi, Sayı:47, ss.213-228.

MHUD, (2004). Denetim Illke ve Esasları. Acar Matbaası, İstanbul.

Müslümov, A., ve Aras, G., (2002). Türkiye'de Muhasebe Ve Finansal Yönetim Uygulamalarında Etik Davranışları Etkileyen Faktörlerin Analizi. XXI Muhasebe Eğitim Sempozyumu, Muğla

Özdemir, E.,(2003). Liderlik ve Etik. Uludag Üniversitesi İktisadi ve İdari Bilimler Fakültesi Dergisi, Cilt XXII, Sayı: 2.ss.121-129.

Wolfe, D., (2004). The Fraud Diamond: Considering the Four Elements of Fraud. CPA Journal, p.38-42

Wells, J. T.. (2001). Why Employees Commit Fraud. Journal of Accountancy, p.89-91. 